\title{
Evaluation and Treatment of Neurogenic Bowel Dysfunction - A Review
}

Lalit Kumar, ${ }^{1,2}$ Eleni Athanasakos ${ }^{1}$ and Anton V Emmanuel 1,2

1. GI Physiology Unit, University College Hospital, London, UK; 2. Division of Medicine, University College London, UK

$\mathrm{N}$ eurogenic bowel dysfunction is a severely troubling entity for patients with neurological disease or injury. The complex symptom cluster presents a challenge, not only for the patients but also for the treating clinician. Without intervention, patients are bound to have a reduced quality of life, and experience social impacts and secondary complications that come along with it. A careful initial assessment provides an idea of symptom severity and is crucial for successful rehabilitation. The mainstay of treatment remains a conservative approach of managing faecal incontinence or optimising the mechanics of defecation to improve patient's quality of life. This article attempts to provide a comprehensive review of existing literature on pathophysiology, assessment and management of neurogenic bowel dysfunction.

\section{Keywords}

Neurogenic bowel dysfunction, bowel dysfunction, hypererflexic bowel, areflexic bowel, upper motor neuron bowel syndrome, lower motor neuron bowel syndrome

Disclosure: Lalit Kumar, Eleni Athanasakos and Anton Emmanuel have nothing to disclose in relation to this article. No funding was received in the publication of this article. This article involves a review of the literature and did not involve any studies with human or animal subjects performed by any of the authors.

Authorship: All named authors meet the International Committee of Medical Journal Editors (ICMJE) criteria for authorship of this manuscript, take responsibility for the integrity of the work as a whole, and have given final approval to the version to be published.

open Access: This article is published under the Creative Commons Attribution Noncommercial License, which permits any non-commercial use, distribution, adaptation and reproduction provided the original author(s) and source are given appropriate credit.

Received: 3 May 2016

Accepted: 25 August 2016

Citation: European Neurological Review, 2016;11(2):109-15

Corresponding Author: Anton V Emmanuel, Gl Physiology Unit, Lower Ground Floor, EGA Building University College Hospital, 25 Grafton Way, London, WC1E 6DB, UK. E: a.emmanuel@ucl.ac.uk
The term 'neurogenic bowel' encompasses the manifestations of bowel dysfunction resulting from sensory and/or motor disturbances ${ }^{1}$ due to central neurological disease or damage. Neurogenic bowel dysfunction (NBD) is a particularly common occurrence in patients with spinal cord injury (SCI), spina bifida and multiple sclerosis (MS) and has been found to worsen progressively in these conditions. ${ }^{2-4}$ Its main symptoms include constipation, faecal incontinence (FI), ${ }^{5}$ evacuation difficulties or a combination of these..$^{4,6-8}$

The significant impact of NBD on patient's life is evident from the number of patients reporting bowel symptoms. For instance, about $95 \%$ of SCI patients report constipation, ${ }^{5} 75 \%$ report at least one episode of $\mathrm{Fl}$ per year whereas $5 \%$ report a daily occurrence of incontinence. The prevalence of constipation and/or $\mathrm{Fl}$ among MS patients ranges from $20 \%$ to $73 \% .{ }^{9,10} \mathrm{~A}$ similar high occurrence of $\mathrm{Fl}$ ranging from $30 \%$ to $50 \%$ has been reported in Parkinson's disease (PD) patients. There is little doubt that NBD affects both the physical and psychological aspects of quality of life and its early recognition and management are vital.

\section{Pathophysiology}

Damage to the spinal cord or brain can interrupt neural pathways. Location and severity of such damage are the key factors in determining colorectal function and the nature and extent of subsequent symptoms. However, it should be kept in mind that symptoms are not always easy to determine and can change with time. For instance, in MS there are often multiple lesions, which keep changing over time and in $\mathrm{SCl}$ the precise level of injury is often not clear during the early stages due to spinal shock, which can last up to 6 weeks. Moreover, the nervous system, being a complex entity, does not always present a fixed clinical pattern even in the same disease or trauma patterns. Broadly, neurogenic bowel symptoms are divided into two patterns depending upon the level of disease or injury being above or below the conus medullaris.

\section{Supraconal disorder - 'upper motor neuron bowel syndrome' or 'hyperflexic bowel'}

This pattern is seen in patients who have disease/injury above the conus medullaris and involves loss of supraspinal inhibitory input resulting in hypertonia of colorectum. The increase in colonic wall, pelvic floor and anal tone results in reduced colonic compliance, overactive segmental peristalsis and underactive propulsive peristalsis. ${ }^{11-13}$ As the peristalsis and haustral movements become less effective the transit slows down throughout the colon. ${ }^{14-16}$ The spastic constricted state of the external anal sphincter (EAS) worsens the situation further by causing retention of stool. The combination of these physiological responses to supraconal injury makes constipation a dominant gut symptom.

Infraconal disorder - 'lower motor neuron type' or 'areflexic bowel' Infraconal lesions are a consequence of disruption of autonomic motor nerves due to damage to parasympathetic cell bodies in the conus medullaris or their axons in the cauda equina. This is characterised by loss of colorectal tone and attenuated rectoanal inhibitory reflex, resulting 
Table 1: Key symptoms to note during initial patient assessment

\begin{tabular}{|l|}
\hline Pre-injury bowel habit \\
\hline Frequency of urge to void rectum \\
\hline Bowel opening frequency \\
\hline Time spent per bowel episode \\
\hline Episodes of urge faecal incontinence \\
\hline Episodes of passive faecal incontinence \\
\hline Meal frequency and content \\
\hline Previous medical history \\
\hline Current and past medication \\
\hline Levels of activity - general mobility, exercise \\
\hline Communication and cognitive ability \\
\hline Psychological and emotional factors \\
\hline Home and care circumstances \\
\hline
\end{tabular}

in a cyclical pattern of insensate rectal filling and progressive rectal distension eventually leading to Fl. ${ }^{5}$ Furthermore, the incontinence is not helped by a reduction in resting and squeeze pressure due to flaccid anal sphincters and laxity of pelvic floor muscles which allows excessive descent of pelvic contents reducing the anorectal angle and opening the rectal lumen. ${ }^{13}$

\section{Clinical features}

NBD is known to restrict everyday activities and limits patients even further, making them feel isolated and housebound. ${ }^{17}$ Both ends of the spectrum; constipation and FI can be present in the affected patient.

Constipation causes significant distress, especially due to its associated symptoms of abdominal bloating, pain and nausea. Impaction with compromised respiratory function as in high-level SCl can even lead to difficulty in breathing caused by reduced diaphragmatic excursion.Chronic constipation can also lead to rectal prolapse, which can lead to a feeling of incomplete evacuation or incontinence, depending upon the severity. The other resultant products of constipation are haemorrhoids and anal fissure. While haemorrhoids usually cause chronic blood loss and perianal itchiness, they can also cause pain similar to anal fissure. The pain from either of these conditions can be severe enough to trigger autonomic dysreflexia in susceptible patients. Autonomic dysreflexia is a medical emergency, as it can lead to potentially life-threatening hypertension in individuals with $\mathrm{SCl}$ above the sixth thoracic vertebrae. Its cardinal sign is rapidly developing severe headache but other signs such as flushing, sweating and blotchiness above the lesion are also commonly observed. Acute autonomic dysreflexia should be treated with sublingual nifedipine or a glycerine trinitrate patch or spray to control blood pressure.

At the other extreme is $\mathrm{Fl}$, which presents its own challenges. It usually leads to social and hygiene problems, skin breakdown and an increase in urinary tract infections. It is known to be one of the symptoms that most seriously affects quality of life in $\mathrm{SCl}$ patients ${ }^{18}$ as it can have a profound effect on a patient's physical, psychological, social and sexual function. ${ }^{19}$

\section{Assessment}

symptom assessment depends on identifying any alarm symptoms that may signify sinister gut pathology, and also identifying what bowel function was like prior to the onset of NBD symptoms. Clinical assessment with a bowel diary can help clarify day-to-day experience, as well as potentially identifying trigger factors to symptoms. The bowel
Table 2: Bedside signs to differentiate supraconal and infraconal disorders

\begin{tabular}{|l|l|}
\hline $\begin{array}{l}\text { Supraconal disorder } \\
\text { (hyperreflexic bowel) }\end{array}$ & $\begin{array}{l}\text { Infraconal disorder } \\
\text { (areflexic bowel) }\end{array}$ \\
\hline High resting anal tone & No/low resting anal tone \\
\hline $\begin{array}{l}\text { Anal reflex present - reflex contraction of } \\
\text { anus in response to stroking of anal skin }\end{array}$ & Anal reflex absent \\
\hline $\begin{array}{l}\text { Bulbocavernosus reflex present - reflex anal } \\
\text { contraction on squeezing glans penis/clitoris }\end{array}$ & Bulbocavernosus reflex absent \\
\hline
\end{tabular}

diary should include details such as number of bowel movements per day, stool consistency, straining during bowel movements and presence of abdominal pain or bloating. The Bristol stool scale can also be used separately to document stool consistency accurately in order to formulate an appropriate management plan. Key current symptoms to note when taking a history are shown in Table $1 .{ }^{20}$

A neurological examination can reveal the severity of injury to the nervous system and the completeness of injury. The abdomen should be inspected for distention. A full physical examination should include rectal examination, which can provide an insight to volitional contraction due to the EAS and the patient's ability to produce voluntary contraction of the puborectalis muscles in addition to providing useful info about the presence of haemorrhoids or masses. ${ }^{21}$ It is vital to establish whether an individual has hyperreflexic or areflexic bowel to help tailor the management accordingly. The clinical signs that can help differentiate between the two conditions are presented in Table 2.

Patients with NBD, in addition to having changes in bowel motility and sphincter control, can also suffer from impaired mobility and hand dexterity, due to coexisting central nervous system pathology. ${ }^{2}$ Thus, the strength of the upper and lower extremities of the patient should also be assessed; their sitting balance and ability to transfer; length of the patient's arms, legs and trunk, and the patient's weight. Such thorough examination will provide an insight to determine whether the patient can perform daily tasks, including bowel management, or whether assistance would be needed.

In addition to the clinical examination, diagnostic tests can be very useful for the clinicians. For instance, an abdominal X-ray can be helpful in confirming and quantifying faecal retention and megacolon. An endoanal ultrasound can identify an external or internal anal sphincter defect and a barium enema or magnetic resonance (MR) proctogram can diagnose paradoxical sphincter contractions. Such prior knowledge can help the clinician formulate an appropriate management plan tailored to an individual's requirements. Anorectal physiology studies can help obtain information on anorectal sensations. However, a digital rectal examination to assess the sphincter contractile strength and pinprick assessment of perineal sensitivity can obviate the need for formal anorectal physiology studies in most cases. Similarly, transit measurement is not needed for most patients - the quantification of urge frequency provides the necessary information (urge that is daily or less often usually signifies slow transit).

\section{Management}

Bowel management in neurogenic gut dysfunction requires the provision of interventions tailored to an individual's needs in order to establish a scheduled and effective bowel evacuation and to prevent 
the associated morbidity. Individuals with hyperreflexic bowel have an intact reflex arc between the spinal cord and colon/anorectum and, as such, the stimulation of the rectum (chemically or mechanically) results in evacuation of stool. On the other hand, individuals with areflexic bowel require gentle valsalva manoeuvres and/or manual evacuation. The aim is to attain a soft stool consistency in hyperreflexic bowel to help easy evacuation and firm-formed stool in areflexic bowel to avoid incontinence episodes. Ironically, despite NBD being a common entity, very little research has been done in this field according to a recent Cochrane review. ${ }^{22}$ Moreover, the evidence that is available is of low methodological quality as per the authors.

The severity of NBD is inversely related to quality of life. Coggrave et al. found that the impact of NBD in SCI patients was significantly greater than other aspects of the disorder. ${ }^{23}$ Several therapeutic approaches exist for the management of neurogenic bowel and although isolated strategies may act as a starting point, more often than not the management is multi-dimensional, involving different treatment modalities. A step-wise approach to managing NBD is shown in Figure 1.

\section{Dietary patterns and lifestyle alteration}

Changing diet to include high fibre content is usually recommended as a first step in the bowel management programme. A systematic review looking at non-neurogenic chronic idiopathic constipation concluded that, although few studies have shown the benefit of using soluble fibre in this patient group, the evidence for using insoluble fibre is conflicting. ${ }^{25}$ Similar results were reported by Markland et al. in their review of more than 10,000 adults, where they found a beneficial effect of increasing fluid intake but not of fibre or exercise in managing constipation. ${ }^{26}$ Looking specifically at individuals with NBD, a case series of $11 \mathrm{SCl}$ patients reported an increase, rather than decrease in colonic transit time with the use of insoluble fibre. ${ }^{27}$ However, the subjects received a very high-fibre diet without proper advice on fluid intake and as such the results are not thought to be relevant to clinical practice. As the insoluble fibre can help bulk and soften the stool, a sensible approach is to adjust its intake according to the stool consistency.

Similar to diet, there is no unanimous opinion about the effects of increased physical activity in managing constipation, as there are a few studies in favour of it28-30 and a few against it..26,31-33 To our knowledge, there has been no study looking at its efficacy in individuals with NBD.

Despite an absence of strong evidence base for these conservative interventions, they have been found to be useful in neurogenic bowel patients. ${ }^{14}$ We support the aim of establishing a pattern of scheduled defecation and exhausting the conservative interventions of dietary and lifestyle modification before moving on to pharmacological interventions. A successful bowel regime will usually be based around the individual's activities and routine, besides taking into account the locally available expertise and resources. In general, scheduled defecation should be attempted once a day or on alternate days. However, it is vital to set the frequency of a bowel programme according to the bowel habits of an individual prior to the injury. For instance, setting up a daily bowel regime for an individual who only ever opened their bowel twice a week prior to spinal injury is simply not going to be successful. Another point to consider while setting the regime is that the bowel contractions are maximal on waking up and after a meal or warm drink (gastrocolic reflex). Although there is no strong evidence for its use in NBD, ${ }^{34,35}$ patients are still advised to make use of gastrocolic reflex by eating or drinking 15-30 minutes before attempting to empty their bowels. ${ }^{36}$
Figure 1: Step-wise approach to treatment of bowel dysfunction

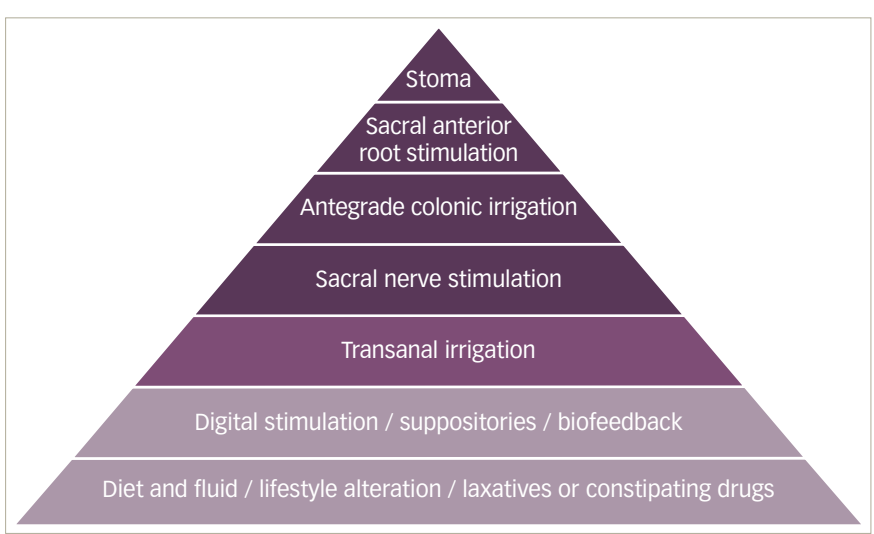

Reproduced with permission from Nature Publishing Group; Consensus review of best practice of transanal irrigation in adults ${ }^{24}$

\section{Abdominal massage}

Abdominal massage has been used as a treatment for chronic constipation since late 1800s as there was a belief that it stimulates peristalsis. ${ }^{37}$ Over the years it fell into disuse, but with growing evidence it has started regaining its popularity and it has reportedly been used by $22-30 \%$ of NBD patients. ${ }^{38,39}$

In a study of $24 \mathrm{SCl}$ patients, abdominal massage added to the standard bowel programme led to a significant reduction in colonic transit time $(90.60 \pm 32.67$ hours versus $72 \pm 34.10$ hours, $p=0.035)$, abdominal distension (45.8\% versus $12.5 \%, \mathrm{p}=0.008)$ and $\mathrm{Fl}(41.7 \%$ versus $16.7 \%$, $\mathrm{p}=0.031$ ), while increasing the frequency of defecation $(4.61 \pm 2.17$ versus $3.79 \pm 2.15, p=0.006){ }^{40}$ Another study by Albers et al. on seven patients with paraplegia secondary to $\mathrm{SCl}$ also found beneficial effects of this technique. ${ }^{41}$ McClung et al., in their study on 30 patients with MS and constipation, found an increase in the frequency of defecation in patients who were taught how to perform abdominal massage as compared to the control group, who were given only bowel management advice. ${ }^{42} \mathrm{~A}$ randomised controlled trial involving patients who suffered cerebrovascular accident reported a reduction in severity of constipation and increased defecation frequency in the group receiving abdominal massage. ${ }^{43}$

Despite the evidence showing this to be an effective technique, its mechanism of action is not entirely clear. Several theories have been proposed, including activation of intestinal stretch receptors, which causes an increase in intestinal and rectal contraction, ${ }^{44}$ elicitation of measurable waves of rectal muscle contraction, ${ }^{45}$ decrease in colonic transit time, ${ }^{40}$ stimulating the parasympathetic nervous system, thereby leading to increase in gut secretions and motility and relaxing sphincters in the digestive tract. ${ }^{46}$ Whatever the mechanism, abdominal massage has a clear advantage of being inexpensive, non-invasive and risk-free.

\section{Oral laxatives}

Oral laxatives are the next step up the ladder in the management of NBD. High-quality data exist in the form of several randomised controlled trials (RCTs) confirming the beneficial effect of laxatives in individuals with NBD. Polyethylene glycol (PEG/Macrogol) has been found to be superior to lactulose in two RCTs, 7,48 leading to higher bowel frequency in both studies ( $p<0.01$ in the first and $p<0.002$ in the second study). Other commonly used laxatives include bisacodyl and senna (colonic stimulants), docusate (stool softener) and fybogel (bulk forming). While osmotic and stimulant laxatives form the mainstay of treatment, several 
Table 3: Antegrade continence enema in adult population

\begin{tabular}{|l|l|l|}
\hline Study & Methods & Main outcomes \\
\hline Basson et al. ${ }^{68}$ & $n=111$ (7 neuropathic) & $\begin{array}{l}\text { Improvement in } 100 \% \text { of } \\
\text { neuropathic patients }\end{array}$ \\
\hline Myers et al. ${ }^{69}$ & $n=15$ (15 neuropathic) & Improvement in $80 \%$ of patients \\
\hline Imai et al. $^{70}$ & $n=21$ (21 spina bifida) & Improvement in $90 \%$ of patients \\
\hline${\text { Teichman et al. }{ }^{71}}^{\text {Im }}$ & $n=7$ (3 spinal cord injury) & $\begin{array}{l}\text { Improvement in } 75 \% \text { of patients } \\
\text { and quality of life }\end{array}$ \\
\hline $\begin{array}{l}\text { Christensen } \\
\text { et al. }{ }^{72}\end{array}$ & $n=8$ (8 spinal cord injury) & $\begin{array}{l}\text { Improvement in } 87 \% \text { of patients } \\
\text { and quality of life }\end{array}$ \\
\hline Teichman et al. $^{73}$ & $\mathrm{n}=7$ (4 spinal cord injury) & Improvement in $100 \%$ of patients \\
\hline
\end{tabular}

other drugs with different mechanisms of action have shown promising results. Cisapride is one such drug which acts as 5-HT4 receptor agonist and, although it was reported to reduce colonic transit time in $\mathrm{SCl}^{49}$ and PD patients, ${ }^{50}$ it has almost fallen into disuse due to its adverse cardiac effects. A newer 5-HT4 receptor agonist, prucalopride has shown an improvement in frequency of bowel movements per week and a significant reduction in colonic transit time in $\mathrm{SCl}$ patients. ${ }^{51}$

Neostigmine, a prokinetic, mediates bowel emptying via an increase in parasympathetic stimulation of the gut, thereby leading to an increase in peristalsis. An RCT of $13 \mathrm{SCl}$ patients found an improved stool expulsion $^{52}$ and a double-blind crossover trial of seven $\mathrm{SCl}$ patients reported a reduction in bowel evacuation time..$^{53}$ Its adverse effects of bradycardia and bronchoconstriction are well known and limit its use to hospital settings. ${ }^{52}$

Other drugs, such as lubiprostone, a chloride channel activator, and linaclotide, a guanylate cyclase $\mathrm{C}$ receptor agonist, cause an increase in fluid secretion into the gut. They have shown some promising results but need further studies to confirm their efficacy in individuals with NBD.

\section{Digital anal stimulation, suppositories and enemas}

Digital stimulation is a well-established technique used in individuals with NBD to help facilitate bowel evacuation. The technique requires the patient or the carer to insert a gloved, lubricated finger into the rectum and move it in a rotatory pattern. It works by dilating the anal canal and relaxing the puborectalis muscle, which leads to a reduction in the anorectal angle. Both of these essentially lead to a reduction in resistance to the passage of stool, thereby assisting bowel emptying.

Shafik et al. in their study on 11 patients, noted left colonic contractions upon rectal distension which were absent after anaesthetising the rectum and anal canal. They named this the recto-colic reflex. ${ }^{54}$ This rectocolic reflex has been found to be useful in initiating bowel movement in individuals with supraconal disorders but not in those with infraconal lesions. Another study on 18 healthy subjects and nine SCI patients found an increase in the rectal pressure in both groups with anal dilatation. ${ }^{55}$ A case series of six $\mathrm{SCl}$ patients by Korsten et al. reported an increase in the frequency of peristaltic waves during digital rectal stimulation (DRS) and in the period immediately after cessation of DRS. This increase in peristalsis was accompanied by expulsion of barium oatmeal, thereby providing evidence for increased left-sided colonic motility. ${ }^{56}$

Overall, DRS is a safe and effective intervention, with the only precaution advised to be gentle to avoid rectal mucosa injuries ${ }^{57}$ and to avoid precipitation of autonomic dysreflexia. ${ }^{58}$ If DRS is not helpful in providing the desired symptomatic relief, it is augmented by the use of suppositories and enemas, which are preferred over manual evacuation of the stool. Glycerine and bisacodyl are the commonly used suppositories, with the latter having either hydrogenated vegetable oil or PEG as a base. Three studies (one good-quality RCT) have reported better results with PEG-based suppositories. ${ }^{59-61}$ Sodium bicarbonate suppositories (Lecicarbon E) release carbon dioxide, which subsequently stimulates the rectal reflex activity are also commonly used. A clinically significant decrease was noted in the amount of nursing time with the use of these suppositories in addition to less requirement for assistance and a reduction in time spent on bowel care. Enemas have been used in the event of suppositories not being helpful. Docusate mini enema has been shown to be more effective in NBD than glycerine or bisacodyl suppositories. ${ }^{59}$ The other enemas commonly used are sodium citrate and sorbitol microenemas (Micralax ${ }^{\circledR}$ ). Large volume phosphate enemas are not routinely used due to difficulty with retention and the risk of triggering autonomic dysreflexia.

\section{Anal plugs}

Anal plugs are disposable devices made of porous foam, which expands rapidly when placed in anal canal, thereby closing the anus. They come in two sizes and the patients are usually given both sizes in order for them to find the size that gives better symptomatic control. Although there have been RCTs looking at their effectiveness, none of these have been in the neurogenic patients. ${ }^{62}$ The side effects noted in different studies include continuing stool leakage, plug loss and local irritation, the latter being uncommon in neurogenic patients. They are quite effective in preventing leakage of stool or gas, as long as it is a small amount. A recent systematic review found that, although there are limited data available regarding their beneficial outcomes, plugs may be helpful in reducing incontinence and its associated problems, provided that patients tolerate and persist with their use..$^{63}$

\section{Antegrade continence enema}

Malone and colleagues are renowned for developing this technique of antegrade irrigation of bowel via an appendicostomy, which acts as a conduit for instillation of tap water or osmotic agent. ${ }^{64} \mathrm{~A}$ valve mechanism prevents leakage of stool through it, while allowing for catheterisation. Caecostomy can be used for patients who had previously undergone appendicectomy. It was initially used in the paediatric population ${ }^{65}$ but over time it gained popularity among adults, in whom a satisfaction rate of over $80 \%$ has been reported at a mean follow-up of 75 months. ${ }^{.6}$

The evidence for its efficacy is limited to only a few retrospective studies in the adult population, but a finding in all these studies is of high satisfaction rates and improvement in quality of life post antegrade continence enema (ACE) procedure in patients with neurogenic bowel (see Table 3). The complications reported with ACE include stenosis, leakage or failure to effectively treat symptoms, thereby requiring a redo surgery. The rate of conversion to a stoma has been reported to be around $30 \% .{ }^{67}$

An alternative to ACE is percutaneous endoscopic colostomy (PEC), in which an enterostomy tube is endoscopically placed in the left colon and acts as an irrigation port. A study of 27 patients undergoing PEC reported symptomatic improvement in $80 \%$ of subjects undergoing the procedure. ${ }^{74}$

\section{Transanal irrigation}

Transanal irrigation (TAI) involves introducing water into the colon via the anus, with the aim of aiding evacuation of contents from the rectum and left-sided colon. Although TAl has been practised since $1500 \mathrm{BC}$, it 
is Shandling and Gilmour who introduced it into modern medicine after using it to achieve faecal continence in children with spina bifida. ${ }^{75}$ Several commercial devices are available with a different design but, for the purpose of this paper, we have used TAl as the broad term (Figure 2).

The use of TAl for the treatment of NBD was established by Christensen et al. in 2006. ${ }^{76}$ In their randomised controlled study of $87 \mathrm{SCl}$ patients with NBD, they compared the use of TAl to conservative bowel management, for a 10-week trial period and found TAI to be superior. The results are summarised in Table 4.

TAl has also been found to be helpful in neurological disease beyond those affecting the spinal cord. Our group has previously reported an improvement of over 50\% in constipation and FI score in $30 \mathrm{MS}$ patients, post-TAl use, who failed to respond to maximal medical treatment for bowel dysfunction. ${ }^{77}$ In individuals experiencing NBD secondary to PD, TAl has been shown to reduce constipation symptoms. ${ }^{78}$ Not all patients will respond favourably to this treatment. Few predictive factors which have been identified as relating to a successful outcome include low rectal volume at urge to defecate, low maximal rectal capacity, male gender, mixed constipation and FI symptoms, and prolonged colonic transit time. ${ }^{78}$

The absolute contraindications include anal stenosis, recent rectal surgery, active inflammatory bowel disease, active diverticulitis, colorectal cancer and ischaemic colitis.95,96 The main complication associated with TAl is bowel perforation. However, the rates for this are pretty low, with an estimated risk of irrigation-induced perforation to be one per 50,000 $(0.0002 \%) .{ }^{79}$ Importantly, this risk is not thought to be cumulative, with the greatest rates of damage occurring early on, especially in poorly selected patients who have not been appropriately trained. ${ }^{97}$

\section{Electrical stimulation therapies}

\section{Sacral anterior nerve root stimulation}

This implantation of sacral anterior nerve root stimulator (SARS) was first reported in 1982 by Brindley et al. and it was developed to control urological symptoms in $\mathrm{SCl}$ patients. ${ }^{80}$ It consists of an implant placed via a laminectomy of L4 to S2. The anterior roots of S2 to S4 are placed within the stimulator and connected to a receiver block, which is controlled by a wireless device. ${ }^{81}$ Although it primarily acts on the bladder, by triggering micturition, suppressing detrusor overactivity and detrusor sphincter dyssynergia, ${ }^{82}$ it is also known to stimulate peristalsis in the distal colon and rectum, thereby increasing the frequency of defecation. ${ }^{83-85}$

Binnie et al. reported a significant increase in defecation in SCl patients implanted with SARS. ${ }^{84}$ Furthermore, an improvement in bowel function in the ability to evacuate spontaneously, reduced requirement of manual help for defecation and an improved quality of life have also been reported. $.55,86$ The utility of SARS as a treatment option for managing bladder dysfunction has been well proven but evidence of its efficacy in managing bowel function is still scarce. A recent systematic review by Worsoe et al. identified only 14 papers that studied use of SARS for bowel dysfunction. They reported that the endpoints varied between studies and in some there was a lack of well-defined endpoints. ${ }^{87}$

\section{Sacral neuromodulation}

Similar to SARS, sacral nerve stimulation (SNS) was also developed for controlling urological symptoms. It took more than a decade for it to be adapted for bowel dysfunction, with the first reported implant for $\mathrm{FI}$ taking place in 1995. It is a two-staged procedure, with the first stage
Figure 2: Peristeen ${ }^{\mathrm{TM}}$ anal irrigation system

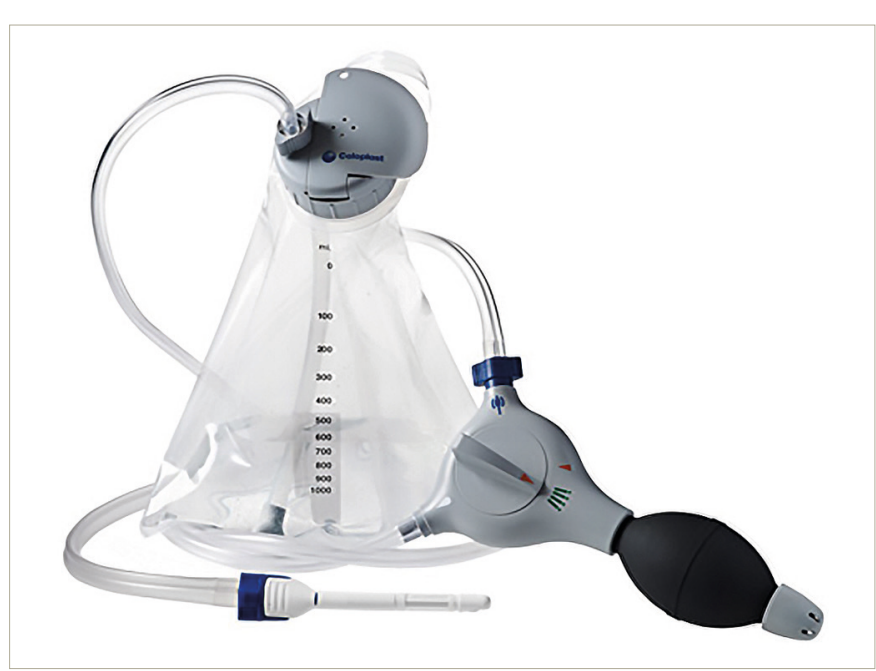

Table 4: Results of randomised controlled trial comparing transanal irrigation to conservative bowel management

\begin{tabular}{|l|l|l|l|}
\hline Scoring system & $\begin{array}{l}\text { Transanal } \\
\text { irrigation } \\
\text { Mean (SD) }\end{array}$ & $\begin{array}{l}\text { Cons bowel } \\
\text { management } \\
\text { Mean (SD) }\end{array}$ & p-value \\
\hline $\begin{array}{l}\text { Cleveland constipation score (0-30; } \\
\text { 30=severe symptoms) }\end{array}$ & $10.3(4.4)$ & $13.2(3.4)$ & 0.0016 \\
\hline $\begin{array}{l}\text { St Mark's faecal incontinence score } \\
\text { (0-24; } 24=\text { totally incontinent) }\end{array}$ & $5.0(4.6)$ & $7.3(4.0)$ & 0.015 \\
\hline $\begin{array}{l}\text { Neurogenic bowel dysfunction score } \\
\text { (0-47; } 14+=\text { severe bowel dysfunction) }\end{array}$ & $10.4(6.8)$ & $13.3(6.4)$ & 0.048 \\
\hline
\end{tabular}

SD $=$ standard deviation

being a trial period of 2-4 weeks, during which a stimulating electrode is placed onto the anterior sacral roots of S2 or S3 via sacral foramina and connected to an external stimulator. If the patient has a satisfactory response, they proceed to the second stage, where a permanent electrode and a pulse generator are implanted.

Although mode of action of SNS is not completely understood, it has been proposed that it controls FI by stimulating the somatic and autonomic nervous system. ${ }^{88} \mathrm{~A}$ few studies have also proposed that it has an effect on the central nervous system. ${ }^{89,90,107,108}$ its effect in cases of constipation has been suggested to be due to an increased frequency of antegrade pressure sequences and high-amplitude pressure sequences. Its role in neurogenic patients has been evaluated by few studies. While schurch et al. reported no improvement in patient symptoms post SNS in complete SCI patients, ${ }^{91}$ several studies have shown a positive clinical outcome of SNS for patients with incomplete SCl. Jarret et al. studied 13 patients with spinal insults (disc prolapse, trauma, spinal stenosis and post-surgery) and reported a decrease in the mean number of incontinence episodes from 9.33 (standard deviation [SD] 7.64) at baseline to 2.39 (SD 3.69) ( $p=0.012)$ at 12 months follow-up. They also reported a significant improvement $(p=0.022)$ in the ability to defer defecation post SNS. ${ }^{92}$ Another study of 29 patients having neurogenic Fl reported marked improvement or complete recovery of continence in 28 patients after a median follow-up of 35 months (range 3-71 months) post SNS. Additionally, there was an improvement noted in quality of life..$^{93}$ Patients with cauda equina syndrome having flaccid paresis of anal sphincters also achieved an improvement in continence after SNS. ${ }^{94}$ Lombardi 
et al., in their study of 29 individuals with NBD (12 with constipation, 11 with $\mathrm{Fl}$ ) reported a significant improvement in Wexner constipation score $(p=<0.05)$ and in Wexner FI score $(p=<0.018)$.

\section{Tibial nerve stimulation}

Stimulation of the tibial nerve can be done using surface electrodes (transcutaneous tibial nerve stimulation; TTNS) or needle electrode (percutaneous tibial nerve stimulation; PTNS). Several studies have reported its efficacy in managing $\mathrm{Fl}$ in non-neurogenic patients but the evidence for its use in NBD is almost non-existent. Mentes et al. reported improvement in the Wexner incontinence score in two $\mathrm{SCl}$ patients post PTNS. ${ }^{95}$ An RCT by Leroi et al. included neurogenic patients, while comparing TTNS with sham stimulation. Although no specific data or analysis were presented specifically for neurogenic patients, it did not report a significant improvement in the number of $\mathrm{Fl}$ episodes or anorectal physiology. ${ }^{96}$

\section{Colostomy/lleostomy}

Stoma formation is usually reserved as a last resort for managing NBD once all other medical treatments have been exhausted. Studies have shown that stoma helps reduce bowel management time, ${ }^{97-100}$ provides independence, ${ }^{98-99}$ reduces the number of hospitalisations ${ }^{100}$ and improves quality of life in neurogenic patients. ${ }^{97,100}$ Moreover, satisfaction rates were found to be high among patients, the majority of whom would have preferred to have the procedure done earlier. ${ }^{97}$ Randell et al. in their study of $52 \mathrm{SCl}$ patients concluded that neurogenic patients with stoma were no worse off than those without, in regard to their general wellbeing and quality of life. ${ }^{101}$

While choosing colostomy for their patients, physicians need to remember that stoma in neurogenic patients carries more complications than in other patients. ${ }^{102}$ Another significant point to remember is that, although stomas can be quite effective in reducing the time spent on bowel care and controlling Fl, they do not correct the colonic transit time and as such, there might be a continual requirement for stoma irrigation or laxative use.

\section{Summary}

A stepwise approach to bowel management, based on a systematic assessment is effective in managing the intrusive gut symptoms that afflict the majority of patients with central neurological disease. Conservative therapy is effective in most patients, with only a minority needing to be considered for as yet not fully proven neuromodulatory therapies or invasive surgical ones. $\square$
1. Chung EA, Emmanuel AV, Gastrointestinal symptoms related to autonomic dysfunction following spinal cord injury, Prog Brain Res, 2006;152:317-33.

2. Krassioukov A, Eng JJ, Claxton G, et al., Neurogenic bowel management after spinal cord injury: a systematic review of the evidence, Spinal Cord, 2010;48:718-33.

3. Williams R, Rigby AS, Airey M, et al., Multiple sclerosis: it [sic] epidemiological, genetic, and health care impact, J Epidemio community Health, 1995;49:563-9.

4. Verhoef $M$, Lurvink $M$, Barf $H A$, et al., High prevalence of incontinence among young adults with spina bifida: description, prediction and problem perception, Spinal Cord 2005;43:331-40

5. Finnerup NB, Faaborg P, Krogh K, Jensen TS, Abdominal pain in long-term spinal cord injury, Spinal Cord, 2008;46:198-203.

6. Glickman S, Kamm MA, Bowel dysfunction in spinal-cord-injury patients, Lancet, 1996;347:1651-3.

7. Stone JM, Nino-Murcia M, Wolfe VA, Perkash I, Chronic gastrointestinal problems in spinal cord injury patients: a prospective analysis, Am I Gastroenterol, 1990;85:1114-9.

8. Hennessey A, Robertson NP, Swingler R, Compston DA, Urinary, faecal and sexual dysfunction in patients with multiple sclerosis, J Neurol, 1999;246:1027-32.

9. Nortvedt MW, Riise T, Frugård J, et al., Prevalence of bladder, bowel and sexual problems among multiple sclerosis patients two to five years after diagnosis, Mult Scler, 2007:13:106-12.

10. Hinds JP, Eidelman BH, Wald A, Prevalence of bowel dysfunction in multiple sclerosis. A population survey, Gastroenterology, 1990;98:1538-42.

11. Banwell JG, Creasey GH, Aggarwal AM, Mortimer JT, Management of the neurogenic bowel in patients with spina cord injury, Urol Clin North Am, 1993;20:517-26.

12. Camilleri $M$, Bharucha $A E$, Gastrointestinal dysfunction in neurologic disease, Semin Neurol, 1996;16:203-16.

13. Stiens SA, Bergman SB, Goetz LL, Neurogenic bowel dysfunction after spinal cord injury: clinical evaluation and rehabilitative management, Arch Phys Med Rehabil, 1997;78(Suppl. 3):S86-102.

14. Krogh K, Nielsen J, Djurhuus JC, et al., Colorectal function in patients with spinal cord lesions, Dis Colon Rectum, 1997:40:1233-9.

15. LeduC $B E$, Spacek E, Lepage $Y$, Colonic transit time after spinal cord injury, I Spinal Cord Med, 1997;20:416-21

16. Nino-Murcia M, Stone JM, Chang PJ, Perkash I, Colonic transit in spinal cord-injured patients, Invest Radiol, 1990;25:109-12.

17. Collings $S$, Norton $C$, Women's experiences of faeca incontinence: a study, Br J Community Nurs, 2004;9:520-3.

18. Pan Y, Liu B, Li R, et al., Bowel dysfunction in spinal cord injury: current perspectives, Cell Biochem Biophys, 2014;69:385-8.

19. DeLisa JA, Kirshblum S, A review: frustrations and needs in clinical care of spinal cord injury patients, I Spinal Cord Med, 1997;20:384-90

20. Coggrave M (Editor), Guidelines for Management of Neurogenic Bowel Dysfunction after Spinal Cord Injury, S.C.I.C.o.t.U.K.a Ireland, 2012 coloplast Ltd: UK, 1-56.

21. Benevento BT, Sipski ML, Neurogenic bladder, neurogenic bowel, and sexual dysfunction in people with spinal cord injury, Phys Ther, 2002;82:601-12

22. Coggrave $M$, Norton $C$, Management of faecal incontinence and constipation in adults with central neurological diseases, Cochrane Database Syst Rev, 2013;12:CD002115.

23. Coggrave M, Norton C, Wilson-Barnett J, Management of neurogenic bowel dysfunction in the community after spinal cord injury: a postal survey in the United Kingdom, Spinal Cord 2008;47:323-33

24. Emmanuel AV, Krogh K, Bazzocchi G, et al., Consensus review of best practice of transanal irrigation in adults, Spinal Cord, 2013;51:732-8

25. Suares NC, Ford AC, Systematic review: the effects of fibre in the management of chronic idiopathic constipation, Aliment the marmacol Ther, 2011:33:895-901.

26. Markland AD, Palsson 0 , Goode PS, et al , Association of low dietary intake of fiber and liquids with constipation:evidence from the National Health and Nutrition Examination Survey, Am J Gastroenterol, 2013;108:796-803.

27. Cameron KJ, Nyulasi IB, Collier GR, Brown DJ, Assessment of the effect of increased dietary fibre intake on bowel function patients with spinal cord injury, Spinal Cord, 1996;34:277-83.

28. Peters HP, De Vries WR, Vanberge-Henegouwen GP, Akkerman LM, Potential benefits and hazards of physical activity and exercise on the gastrointestinal tract, Gut, 2001;48:435-9.

29. de Oliveira, EP, Burini RC, The impact of physical exercise on the gastrointestinal tract, Curr Opin Clin Nutr Metab Care, 2009;12:533-8.

30. Speelman $A D$, van de Warrenburg $B P$, van Nimwegen $M$, et al, How might physical activity benefit patients with Parkinson disease? Nat Rev Neurol 2011:7:528-34.

31. Meshkinpour $\mathrm{H}$, Selod S, Movahedi $\mathrm{H}$, et al., Effects of regular exercise in management of chronic idiopathic constipation, Dig Dis Sci, 1998;43:2379-83.

32. Wald A, Constipation in the Primary Care Setting: Current Concepts and Misconceptions, Am J Med, 2006;119:736-9.

33. Robertson G, Meshkinpour H, Vandenberg K, et al., Effects of exercise on total and segmental colon transit, $J$ Clin Gastroenterol, 1993;16:300-3.

34. Aaronson MJ, Freed MM, Burakoff R, Colonic myoelectric activity in persons with spinal cord injury, Dig Dis SCi, 1985;30:295-300.

35. Menardo G, Bausano G, Corazziari E, et al., Large-bowel transit in paraplegic patients, Dis Colon Rectum, 1987;30:924-8.

36. Walter SA, Morren GL, Ryn AK, Hallböök O, et al., Rectal pressure response to a meal in patients with high spinal cord injury, Arch Phys Med Rehabil, 2003;84:108-11.

37. Sinclair $\mathrm{M}$, The use of abdominal massage to treat chronic constipation, J Bodyw Mov Ther, 2011;15:436-45.

38. Han TR, Kim JH, Kwon BS, Chronic gastrointestinal problems and bowel dysfunction in patients with spinal cord injury, Spina cord, 1998;36:485-90.

39. Coggrave M, Neurogenic continence. Part 3: Bowe management strategies, Br J Nurs, 2008;17:962-8.

40. Ayaş S, Leblebici B, Sözay S, et al., The effect of abdominal massage on bowel function in patients with spinal cord injury, Am J Phys Med Rehabil, 2006;85:951-5.

41. Albers B, Cramer H, Fischer A, et al., [Abdominal massage as intervention for patients with paraplegia caused by spinal cord injury-a pilot study], Pflege Z, 2006;59:2-8.

42. McClurg D, Hagen $S$, Hawkins $S$, et al , Abdominal massage for the alleviation of constipation symptoms in people with multiple sclerosis: a randomized controlled feasibility study, Mult Scler, 2011:17:223-33.

43. Jeon SY, Jung HM, [The effects of abdominal meridian massage on constipation among CVA patients], Taehan Kanho Hakhoe Chi, 2005;35:135-42.

44. Brookes SJH, Chen BN, Costa M, Humphreys CMS, Initiation of peristalsis by circumferential stretch of flat sheets of guinea-pig ileum, J Physiol, 1999:516:525-38.

45. Liu Z, Sakakibara R, Odaka T, et al., Mechanism of abdominal massage for difficult defecation in a patient with myelopathy (HAM/TSP), J Neurol, 2005;252:1280-2.

46. Lämås $\mathrm{K}$, Lindholm L, Stenlund $\mathrm{H}$, et al., Effects of abdomina massage in management of constipation-A randomized controlled trial, Int J Nurs Stud, 2009;46:759-67.

47. Rendeli C, Ausili E, Tabacco F, et al., Polyethylene glycol 4000 vs. lactulose for the treatment of neurogenic constipation in myelomeningocele children: a randomized-controlled clinical myelomeningocele children: a randomized-cont

48. Zangaglia R, Martignoni E, Glorioso M, et al., Macrogol for the treatment of constipation in Parkinson's disease. A randomized placebo-controlled study, Mov Disord, 2007;22:1239-44.

49. Geders JM, Gaing A, Bauman WA, Korsten MA, The effect of cisapride on segmental colonic transit time in patients with spinal cord injury, Am J Gastroenterol, 1995;90:285-9.

50. Jost WH, Schimrigk K, Cisapride treatment of constipation in Parkinson's disease, Mov Disord, 1993;8:339-43.

51. Krogh K, Jensen MB, Gandrup P, et al., Efficacy and tolerability of prucalopride in patients with constipation due to spinal cord injury, Scand I Gastroenterol, 2002;37:431-6.

52. Korsten MA, Rosman AS, Ng A, et al., Infusion of NeostigmineGlycopyrrolate for Bowel Evacuation in Persons with Spinal Cord Injury, Am I Gastroenterol, 2005;100:1560-5.

53. Rosman AS, Chaparala G, Monga A, et al., Intramuscular neostigmine and glycopyrrolate safely accelerated bowel evacuation in patients with spinal cord injury and defecatory disorders, Dig Dis Sci, 2008;53:2710-3.

54. Shafik A, Recto-colic reflex: role in the defecation mechanism, Int Surg, 1996;81:292-4.

55. Shafik A, El-Sibai O, Shafik IA, Physiologic basis of digital-recta stimulation for bowel evacuation in patients with spinal cord injury: identification of an anorectal excitatory reflex, I Spinal Cord Med, 2000;23:270-5.

56. Korsten MA, Singal AK, Monga A, et al., Anorectal stimulation causes increased colonic motor activity in subjects with spinal cord injury, I Spinal Cord Med, 2007;30:31-5.

57. Wang F, Frisbie JH, Klein MA, Solitary rectal ulcer syndrome (colitis cystica profunda) in spinal cord injury patients: 3 case reports, Arch Phys Med Rehabil, 2001;82:260-1.

58. Kewalramani LS, Autonomic dysreflexia in traumatic Kewalramani LS, Autonomic dysreflexia in tr
myelopathy, Am J Phys Med, 1980:59:1-21.

59. House JG, Stiens SA, Pharmacologically initiated defecation for persons with spinal cord injury: effectiveness of three agents, Arch Phys Med Rehabil, 1997;78:1062-5.

60. Dunn KL, Galka ML, A comparison of the effectiveness of Therevac SB and bisacodyl suppositories in SCl patients' bowe programs, Rehabil Nurs, 1994;19:334-8.

61. Frisbie JH, Improved bowel care with a polyethylene glycol based bisacadyl suppository, I Spinal Cord Med, 1997:20:227-9.

62. Paris G, Gourcerol G, Leroi AM, Management of neurogenic bowel dysfunction. Eur J Phys Rehabil Med, 2011:47:661-76.

63. Deutekom M, Dobben AC, Plugs for containing faecal incontinence, Cochrane Database Syst Rev, 2012;4:Cd005086.

64. Malone PS, Ransley PG, Kiely EM, Preliminary report: the antegrade continence enema, Lancet, 1990:336:1217-8.

65. Koyle MA, Kaji DM, Duque M, et al., The Malone antegrade continence enema for neurogenic and structural fecal incontinence and constipation, J Urol, 1995:154:759-61.

66. Worsøe J, Christensen P, Krogh K, et al., Long-term results of antegrade colonic enema in adult patients: assessment of functional results, Dis Colon Rectum, 2008;51:1523-8.

67. Meurette G, Lehur P-A, Coron E, Regenet N, Long-term results of Malone's procedure with antegrade irrigation for severe chronic constipation, Gastroenterol Clin Biol, 2010;34:209-12. 
68. Basson S, Zani A, McDowell S, et al., Antegrade continence enema (ACE): predictors of outcome in 111 patients, Pediatr Surg Int 2014:30:1135-41.

69. Myers JB, Hu EM, Elliott SP, et al., Short-term outcomes of Chait Trapdoor for antegrade continence enema in adults, Urology, 2014;83:1423-6.

70. Imai K, Shiroyanagi Y, Kim WJ, et al., Satisfaction after the Malone antegrade continence enema procedure in patients with spina bifida, Spinal Cord, 2014;52:54-7.

71. Teichman JM, Zabihi N, Kraus SR, et al., Long-term results for Malone antegrade continence enema for adults with neurogenic bowel disease, Urology, 2003;61:502-6.

72. Christensen P, Kvitzau B, Krogh K, et al., Neurogenic colorectal dysfunction - use of new antegrade and retrograde colonic wash-out methods, Spinal Cord, 2000;38:255-61.

73. Teichman JM, Harris JM, Currie DM, Barber DB, Malone antegrade continence enema for adults with neurogenic bowel disease, J Urol, 1998:160:1278-81.

74. Cowlam S, Watson C, Elltringham M, et al., Percutaneous endoscopic colostomy of the left side of the colon, Gastrointest Endosc, 2007:65:1007-14.

75. Nasher $\mathrm{O}$, Hill RE, Peeraully R, et al., Peristeen $®$ Transanal Irrigation System for Paediatric Faecal Incontinence: A single Centre Experience, International Journal of Pediatrics, 2014;2014:954315

76. Christensen P, Bazzocchi G, Coggrave M, et al., A randomized, controlled trial of transanal irrigation versus conservative bowe management in spinal cord-injured patients, Gastroenterology 131(3):738-47.

77. Preziosi G, Storrie J, Boulos P, Emmanuel A, Peristeen ${ }^{\circledR}$ transanal irrigation in patients with multiple sclerosis, $G$ ut 2011:60(Suppl. 1):A29-A29.

78. Faaborg PM, Christensen P, Kvitsau B, et al., Long-term outcom and safety of transanal colonic irrigation for neurogenic bowel dysfunction, Spinal Cord, 2009:47:545-9.

79. Christensen P, Krogh K, Buntzen S, et al., Long-term outcome and safety of transanal irrigation for constipation and fecal incontinence, Dis Colon Rectum, 2009:52:286-92.

80. Brindley GS, Polkey CE, Rushton DN, Sacral anterior roo stimulators for bladder control in paraplegia, Paraplegia 1982:20:365-81.

81. Kutzenberger J, Surgical therapy of neurogenic detrusor overactivity (hyperreflexia) in paraplegic patients by sacral deafferentation and implant driven micturition by sacral anterior root stimulation: Methods, indications, results, complications, and future prospects, Acta Neurochirurgica, Supplementum, 2007;333-9.

82. Sauerwein D, Operative therapy of the spastic bladder: Sacral deafferentation and anterior root stimulation, Urologe Ausgabe A, 1990;29:196-203.

83. Varma JS, Binnie N, Smith AN, et al., Differential effects of sacra anterior root stimulation on anal sphincter and colorectal motility in spinally injured man, Br J Surg, 1986;73:478-82.

84. Binnie NR, Smith $A N$, Creasey $G H$, Edmond $P$ Constipation associated with chronic spinal cord injury: The effect of pelvic parasympathetic stimulation by the Brindley stimulator, Paraplegia, 1991;29:463-9.

85. MacDonagh RP, Sun WM, Smallwood R, et al., Control of defecation in patients with spinal injuries by stimulation of sacral anterior nerve roots, Br Med I, 1990;300:1494-7.

86. Kachourbos MJ, Creasey GH, Health promotion in motion: improving quality of life for persons with neurogenic bladder and bowel using assistive technology, SCI Nurs, 2000;17:125-9.

87. Worsøe J, Rasmussen M, Christensen P, Krogh K Neurostimulation for Neurogenic Bowel Dysfunction, Gastroenterol Res Pract, 2013;2013:8

88. Gourcerol G, Vitton V, Leroi AM, et al., How sacral nerve stimulation works in patients with faecal incontinence, Colorectal Dis, 2011;13:e203-e211.

89. Griffin $\mathrm{KM}$, Pickering $\mathrm{M}, \mathrm{O}^{\prime}$ Herlihy $\mathrm{C}$, et al., Sacral nerve stimulation increases activation of the primary somatosensory cortex by anal canal stimulation in an experimental model, $\mathrm{Br} J$ surg, 2011;98:1160-9.

90. Sheldon R, Kiff ES, Clarke $A$, et al., Sacral nerve stimulation reduces corticospinal excitability in patients with faecal incontinence, Br J Surg, 2005;92:1423-1.

91. Schurch B, Reilly I, Reitz A, Curt A, Electrophysiological recordings during the peripheral nerve evaluation (PNE) test in complete spinal cord injury patients, World I Urol, 2003;20:319-22

92. Jarrett MED, Matzel KE, Christiansen J, et al., Sacral nerve stimulation for faecal incontinence in patients with previous partial spinal injury including disc prolapse, Br J Surg, 2005;92:734-9.

93. Holzer B, Rosen HR, Novi G, et al., Sacral nerve stimulation for neurogenic faecal incontinence, $B r J$ Surg, 2007;94:749-53

94. Gstaltner K, Rosen H, Hufgard J, et al., Sacral nerve stimulatio as an option for the treatment of faecal incontinence in patients suffering from cauda equina syndrome, Spinal Cord, 2008;46:644-7

95. Mentes BB, Yüksel O, Aydin A, et al., Posterior tibial nerve stimulation for faecal incontinence after partial spinal injury: preliminary report, Tech Coloproctol, 2007;11:115-9.

96. Leroi AM, Siproudhis L, Etienney I, et al., Transcutaneous electrical tibial nerve stimulation in the treatment of fecal incontinence: a randomized trial (CONSORT 1a), Am J Gastroenterol, 2012;107:1888-96.

97. Safadi BY, Rosito O, Nino-Murcia M, et al., Which stoma works better for colonic dysmotility in the spinal cord injured patient? Am J Surg, 2003;186:437-42.

98. Munck J, Simoens $\mathrm{CH}$, Thill V, et al., Intestinal stoma in patients with spinal cord injury: a retrospective study of 23 patients, Hepatogastroenterology, 2008;55:2125-9.

99. Branagan $\mathrm{G}$, Tromans, Finnis D, Effect of stoma formation on bowel care and quality of life in patients with spinal cord injury Spinal Cord, 2003;41:680-3.

100. Rosito O, Nino-Murcia M, Wolfe VA, et al., The effects of colostomy on the quality of life in patients with spinal cord injury:a retrospective analysis, I Spinal Cord Med, 2002;25:174-83.

101. Randell N, Lynch AC, Anthony A, et al., Does a colostomy alter quality of life in patients with spinal cord injury? A controlled quality of life in patients with spinal
study, Spinal Cord, 2001;39:279-82.

102. Preziosi G, Emmanuel A, Neurogenic bowel dysfunction: pathophysiology, clinical manifestations and treatment, Expert Rev Gastroenterol Hepatol, 2009;3:417-23. 